\section{ENDOCRINE DISORDERS IN CHILDHOOD AND ADOLESCENCE}

By H. S. Le Marquand, M.D., F.R.C.P., F. H. W. Tozer, M.D., M.R.C.P., and W. J. Tindall, M.D. 2nd Edition. Pp. xiii +332 , illustrated. London: English Universities Press Ltd. 1954. 32s. $6 \mathrm{~d}$.

The second edition of this popular little textbook has grown in size and has acquired a new contributor, Dr. Tindall, who has re-written the chapter on the physiology of the endocrine glands, without, however, influencing the rather unscientific outlook of the remainder of the book. This is exemplified by the retention of tables of body measurements derived from Engelbach (1932) in the form of minimum and maximum values without any indication as to what these terms mean, when applied to physiological variables.

However, one can sympathize with the authors' difficulties in this respect, because, while there are recent anthropometrical studies which include standard deviations and percentile figures (e.g. Report on the Height and Weight of School Pupils in the County of London in 1949 . L.C.C. Report No. 3692) they concern only certain measurements or certain age groups.

The authors are rightly proud that their book is ' the product of a county hospital' and they have certainly made good use of their clinical material in giving a valuable account of the natural history of the commonest endocrine disorder of childhoodobesity, a subject given scant attention in other text books. In contrast a county hospital cannot provide many examples of the manifold oddities of endocrine dysfunction and the authors have to make use of the ' literature' to describe those conditions of which they have little personal experience. This gives the book an uneven quality. It is a criticism which could be levelled at many medical textbooks that by including rare disorders, they lose in authority more than they gain in comprehensiveness.

As the only textbook on paediatric endocrinology published in this country, it will continue to have a wide popularity. The authors are to be commended for the long list of references, but the reviewer hopes that the titles of each paper will be added in the third edition.

\section{MIGRAINE AND PERIODIC HEADACHE}

By Nevil Leyton, M.A., M.R.C.S., L.R.C.P. Second Edition. Pp. xii + 128 . Lọdon: Wm. Heinemann Ltd. 1954. I2s. 6d.

In this short book, written for lay and professional readers, Dr. Leyton considers the therapeutic problem of migraine and periodic headaches; he divides these into a group caused by endocrine upset, and an allergic group. Treatment of the endocrine group, the author recommends, should be with an 'Anterior Pituitary-like' hormone (A.P.L.) pre- pared from pregnancy urine, which is said to via the pituitary on the gonads. Allergic cases ' desensitized ' to prostigmin or histamine. Certaign adjuvant therapies are then described including Carbachol, Urea, Bellergal and the Vitamin $B$ complex, and, inevitably, A.C.T.H. Analgesies and ergot derivatives are given short shrift. The results of these treatments on 1,765 cases fक्षेe assembled in twelve lines on page 57.

Assessment of the value of a therapeutic measute in disease is often a matter of great difficulty. Of the many factors to be considered perhaps the mos important are the natural history of the disease, - definition of the variable studied, careful control $8 f$ each act of the therapeutic process and, above alt, measures to eliminate the enthusiasms and prejudicas of the observer. This book fulfils none of these criteria and fails most lamentably in the last.

Certain diseases appear to be influenced more the enthusiasm of the doctor for a particular line of treatment than by the treatment itself; in the face of this, one cannot agree with Dr. Leyton when says '. . . the treatment of a parallel series of cases one by one method and a second by another, for thife purposes of control is, in the opinion of the author, not only unjustified but useless for evaluation in $-\mathrm{a}$ disease the basic cause of which varies so greater and which presents with such a wide range fof symptoms.'

However, what the book fails to offer in intellecctual satisfaction it supplies in emotional appeal.

\section{CLINICAL ENDOCRINOLOGY}

By Karl E. Paschkis, M.D., Abraham E. Rakoro M.D., and Abraham Cantarow, M.D. Pp. æू. +830 , with 253 illustrations, five in colou? London: Cassell \& Co. Ltd. r954. Ir 8s. 6d.

This newcomer to the well-stocked field of textbooks on endocrinology is intended for the medical student and the interested general practitioner. Ft makes no pretence at an exhaustive coverage of the field and is therefore of limited value to the specialist. It attempts, on the whole successfully, a synthesis between scientific and practical medicine, and, in the best modern tradition, each section, devoted to the study of a special endocrine gland, begins with adequate account of the anatomy, embryolog $\vec{s}$, physiology, and pathology of the gland being cors sidered. A useful chapter near the end discusses procedures and methods of investigation. In the reviewer's opinion this might be almost the most important part of a textbook of endocrinology, anet this chapter would be improved by further amplin fication and the use of diagrams. The description of the water diuresis test (Kepler) is quite inadequate and contains no reference to its possible dangers. The use of cortisone as a diagnostic procedure (e. to modify the water excretion test) is not mentioned

On the whole this is a good book and can con'fidently be recommended to students, pre- and post graduate alike. 